\title{
Introducing SMART Table Technology in Saudi Arabia Education System
}

\author{
Gafar Almalki \\ (School of Education and \\ Professional Studies) \\ Griffith University \\ Gold Coast, Australia
}

\author{
Professor Glenn Finger \\ (School of Education and \\ Professional Studies) \\ Griffith University \\ Gold Coast, Australia
}

\author{
Dr Jason Zagami \\ (School of Education and \\ Professional Studies) \\ Griffith University \\ Gold Coast, Australia
}

\begin{abstract}
Education remains one of the most important economic development indicators in Saudi Arabia. This is evident in the continuous priority of the development and enhancement of education. The application of technology is crucial to the growth and improvement of the educational system in Saudi Arabia. Introducing SMART Table technology in the Saudi Arabian education system is argued in this paper as being able to assist teachers and students in the process of accommodating both technological changes and new knowledge. SMART Tables also can enhance the level of flexibility in the educational system, thus improving the quality of education within a modern Saudi Arabia. It is crucial to integrate technology effectively and efficiently within the educational system to improve the quality of student outcomes. This study will consider the potential benefits and recommendations associated with the adoption of SMART Tables in Saudi Arabian education system.
\end{abstract}

Keywords-ICT; Smart Table; education; barrier;
implementation

\section{INTRODUCTION - SMART TABLE TECHNOLGY}

SMART Table technology referred to throughout this paper is the registered trademark of SMART Table collaborative learning centres (see, for example, http://smarttech.com/table). SMART Table represents a relatively new technology in the form of a multi-touch interactive learning centre that is designed for effective and efficient use for primary pupils.

The application of technology in the education system offers the opportunity for primary pupils to interact, discuss, and share information in the process of grasping vital knowledge from their teachers. SMART Table technology enables the pupils to collaborate, discuss, and enhance their knowledge through digital aspects of education. The students have the opportunity to explore digital lessons, participate in the educational games, and form teams as an element of working together in the search for relevant solutions. The technology is multi-user in its design to enable numerous pupils to participate in the interaction and discussion at the same time. The table provides unlimited opportunities for students in relation to enjoy learning and expressing elements of teamwork. The designing of the table makes it vital and relevant to the primary pupils and their teachers (Ghavifekr \& Ghani 2011, p. 86).

The table is designed with a durable surface that is suitable for the requirements of the primary pupils in the pursuit of education. The application of networking system in the form of wireless connections enables students to share during the learning process. Teachers also have the opportunity to design the learning objectives and activities within the table to enhance the process of transmitting information to the pupils. This is receiving positive acceptance from the teachers and students in Saudi Arabia, where it is being implemented, because of the ability to encourage connections between the learners and the teachers.

SMART Tables are also durable in their design in enabling education programs for a diverse range of students. A strength is the ease in which it can be used and has the capacity to support up to six users at a time. In addition, the table demonstrates numerous further benefits in relation to its implementation in the educational system of Saudi Arabia. This reflects development towards the achievement of quality education that would promote growth and development of the nation (Kian-sam 2011, p. 1279).

\section{BenEFITS OF THE SMART TABLE TECHNOLOGY}

SMART Tables being implemented in the educational system of Saudi Arabia provide the opportunity for the primary pupils to learn together and this is creative in nature since the pupils have the chance to express their knowledge with their peers. The pupils can make learning gains through the process of learning in the presence of other pupils.

Enjoyment for learning is enhanced through the implementation of the table as it enables the pupils to view the process of knowledge generation and acquisition as a game to be played. The learning process is creative, and has the ability to differentiate and personalize instructions with the aim of supporting a variety of learning styles in fun and engaging forms. The learning process is similar to playing environments whereby pupils interact with their teachers effectively and efficiently. This is vital towards the grasping of the crucial information from the between students and their teachers (AlFahad 2010, p. 67).

The teachers and students develop important collaborations thus creating a virtual environment to foster learning process. It is beneficial for students to grasp the fundamental aspects of knowledge at initial stages to promote their development as they progress within the educational system. Application of SMART Table provides the opportunity to ensure that each student has an equal chance of 
succeeding in the process of grasping essential knowledge. The table also enhances teamwork in the pursuit of education thus the opportunity to improve the creative environment.

\section{A. SMART Table and English Language Learning}

SMART Table also aims at minimizing the barriers that limit the ability of pupils to learn English language needed for their development through the learning process. The application of the table system in Saudi Arabia provides students with the opportunity to enjoy virtual aspect of knowledge, and this includes approaches which promote the ability to learn English language through using SMART Tables.

The interactive products play an important role in the development of virtual information to generate development and awareness of the students. It is also crucial for students to grasp the English language with minimal time possible to enhance further development. Further research is needed to determine if SMART Table can enable faster acquisition of English language proficiency. English language also develops through application of numerous products and interactive sessions using SMART Tables. The pupils develop the ability to communicate in English. The ability to learn collaboratively reduces anxiety in the pupils thus creates an environment to learn English language and relevant subject-area content. During the sessions, all students can engage in discussion and providing the opportunity to explain and share English words. There are substantial opportunities for students to see, listen, and interact with the available learning products or materials. This makes the learning process to be meaningful to the pupils hence the motivational aspect in relation to learning and participating in the classroom activities.

\section{B. SMART Table and Enhancing Education}

SMART Table enables the educational system in Saudi Arabia to create vibrant and meaningful lessons. This is possible through the application of the physical world into the classroom environment. This relationship makes the learning process interactive and user friendly, hence pupils understand the concepts with ease. The application of technology enables students to ask questions, discover, and collaborate with teachers thus the opportunity to explore and learn effectively and efficiently. Within the context of Saudi Arabia, SMART Table provides the opportunity for pupils to instill lifelong interest in science, technology, engineering, and mathematics. This can enable the educational system to improve academic achievement in relation to the pupils in need of knowledge. Teachers also play a critical role in encouraging pupils to participate in the learning process. This is possible through the provision of opportunities to hear, see, and touch the lesson products or materials.

\section{SMART Table and Student Support}

SMART Table is also useful in promoting accessibility through providing students with relevant support through visual, auditory, physical and mobility. These elements enable the student to satisfy their social and communication needs. This makes it easy for students to interact both academically and socially within the class environment. Creation of support in the pursuit of education is vital in the provision of equal opportunity to students to enhance their understanding on the concepts. The students have the chance to express themselves, interact with relevant learning activities, and perceive appropriate concepts. The table is essential towards tailoring of instruction that relates to each student with the aim of creating ample environment to achieve academic and social goals.

\section{SMART Table and Flexibility}

SMART Table enhances flexibility in relation to the teaching style and content of the educational system in Saudi Arabia. SMART Table comes with a toolkit that enables teachers to create numerous activities within the learning centre. The toolkit is also essential in the customization of activities that are new and ready-made in nature. In the process of learning, it is critical to redesign activities with the aim of keeping students challenged or engaged. The students have the opportunity to interact with the teachers and fellow students equally and freely thus accurate and effective learning process.

SMART Table complements the application of SMART Board interactive whiteboard and other interoperable technologies. This leads to the accommodation of numerous teaching styles and is advantageous to student learning. The educational system in Saudi Arabia has the opportunity to develop interactive lessons between the whole-class or within the small learning groups. The modern students are often techsavvy, and hence appreciate the application of SMART Table as an interactive learning centre. The horizontal and 360 degree surface provides the opportunity for students to enjoy the learning process and collaborate with each other.

The educational system in Saudi Arabia enables students to build cognitive, social, and acute motor skill. This is possible through implementation of SMART Table activities within the educational system. The system caters for students who are usually shy to participate effectively and demonstrate leadership abilities through the completion of group tasks. The table has different features that are engaging in the process of pursuing knowledge. The table system is accessible to all students including the pupils with exceptional needs.

\section{E. SMART Table and IT Applications}

SMART Table has the opportunity to integrate notebook and laptop software. This promotes the transfer of files and data from the main computer to the learning centre. The learning activities reflect on the table to provide students with prior information on the topic of concern. This is crucial towards the achievement of social and academic goals. The students also have the opportunity to capture the images through document camera. The captured images are applicable in the process of learning within the interactive centre (Karfash 2010, p. 67).

The Saudi government utilizes significant financial resources to enhance the education portfolio. For example, besides offering free education, the Saudi government provides its students with free learning tools, health services, and living expenses if necessary. As a result of its focus on education over the many years, the number of children at School increased from 547,000 students in 1970 to more than 
five million students in 2007, and the majority of these students attend nearly 32,000 public schools as shown in Table 1 (Vanderlinde, Braak \& Tondeur, 2010).

TABLE I.

SCHOOLS AND STUDENTS 1970-2007

\begin{tabular}{|l|l|l|l|l|}
\hline Year & Schools & Girls & Boys & students \\
\hline & Number & “000” & “000” & “000” \\
\hline 1970 & 3,282 & 135 & 412 & 547 \\
\hline 1975 & 5,634 & 311 & 673 & 984 \\
\hline 1980 & 11,070 & 511 & 951 & 1,462 \\
\hline 1985 & 15,079 & 876 & 1,273 & 2,149 \\
\hline 1990 & 16,609 & 1,310 & 1,624 & 2,934 \\
\hline 1995 & 21,284 & 1,912 & 2,022 & 3,934 \\
\hline 2000 & 22,770 & 2,369 & 2,404 & 4,774 \\
\hline 2004 & 29,807 & 2,403 & 2,379 & 4,783 \\
\hline 2007 & 31,798 & 2,496 & 2,522 & 5,019 \\
\hline
\end{tabular}

As noted, this increase in students and the resources essential for their education places substantial strains on an education system which is still comparatively new and which needs considerable improvement in its standards to adhere to the needs of economic growth, a civil society, and international prospects. The aim of this paper is to make the case for the implementation of Smart Table technologies into Saudi Arabia Education System in order to meet those needs, and complement the use of other technologies in the learning and teaching environment.

\section{F. Barriers to Implementing ICT and SMART Table Technologies}

SMART Table has a potential to enhance the methods of teaching and learning. However, there are some barriers that hinder the integration or rather the implementation of the SMART Table technology into the education system. Choy, Berkner, Yopper \& Department of Education (ED) (2010) assert that, even though teachers accept the significance of ICT to enhance the education system, some challenges arise in the process of integrating these technologies. This section highlights several barriers on the implementation of both ICT and SMART Table technologies into the educational system.

While the integration of ICT and SMART Table into education may have the potential to generate positive changes in teaching and learning environments, this process is difficult. Barriers to ICT and SMART Table integration vary from case to case, depending on the existing environments of the country, society, education, school, teachers and conceivably the students. This section, therefore, seeks informed commentaries about issues which may relate to developing countries, and to Arab societies.

As mentioned above, there are many and various issues in integrating ICT and SMART Table in any given curriculum, including both external and internal barriers to reform (KianSam \& Songan, 2011).

According to Bose (2010), the barriers comprise a lack of access to computers and software, inadequate time to plan instruction, lack of technical and administrative support and inadequate resources. Vanderlinde, Braak \& Tondeur (2010) adds to these barriers the establishment and on-going costs of providing sufficient ICT for teachers. The external environment barriers include systems outside individual schools, for instance, educational districts, communities, and the larger society. There is a lot of criticism about Education having isolated itself from the local and the larger society. Societal involvement during technology planning with new pedagogy is an indispensable part of structuring a sustainable system (Kaveie, 2011). These barriers are discussed below as intrinsic and extrinsic barriers that impede implementation, and environmental issues.

\section{A. Intrinsic Barriers}

Intrinsic barriers refer to individual teacher dimensions, such as confidence, motivation and attitudes towards using technology. For example, Scott (2009) in a research study observing and interviewing teachers who attained different levels of ICT integration found that even though external barriers restrained all teachers' attempts in the school, individual teachers reacted in different ways to these external constraints, based largely in part on an individual teacher's evaluation and design of efficient classroom practice. In another study, Scott (2009) stated that the affiliation between a lack of teacher self-assurance and teachers' computer unease, and the lack of teacher competency were internal barriers or intrinsic factors, while the lack of access to ICT and resources were external barriers or extrinsic factors (see Figure 3).

As technology in education changes, pre-service teachers entering into the classroom may be the first in a school to initiate new techniques or take alternative paths to engaging students in learning experiences. SMART Table is an example of a new technology being introduced in modern education systems.

It is possible as well for some teachers to refuse to incorporate new technologies which might disrupt their historical approaches to curriculum design and implementation, based upon arguments that they achieved positive outcomes prior to the introduction of the new technologies. Caution is needed not to interpret this resistance to change may be "as anti-progressive or technophobia" Alenezi, Karim, \& Veloo (2010). On the other hand, even when teachers are convinced that the new technology is worthwhile adopting, there may be numerous intrinsic factors that prevent teachers from using the SMART Table technology in their teaching. Kian-Sam \& Songan (2011) indicate that the intensity of teachers' training and skills are important factors that influence the implementation of ICT and SMART Table technologies. Also, Choy, Berkner, Lee Topper, \& Department of Education (ED) (2009) note that opposing change relates to SMART Table strategy anxiety through several factors: psychological, sociological, and outfitted. There is perhaps a causal correlation between the 
external and internal barriers (Ghavifekr, Hussin, \& Ghani, 2011).

To implement SMART Table effectively into the curriculum, teachers require proficiency in ICT skills as well as instructive knowledge of efficient ICT teaching practices. Intrinsic variables in ICT integration include positive teaching skills with computers; teacher's confidence with computers; viewpoints supporting the use of computers as an educational tool; training; inspiration; support; and teaching efficiency Ghavifekr, Hussin, \& Ghani, (2011) and Kian-Sam \& Songan, (2011) found that quality of training and inadequate time as barriers that put off teachers from integrating SMART Table and ICT into the classroom.

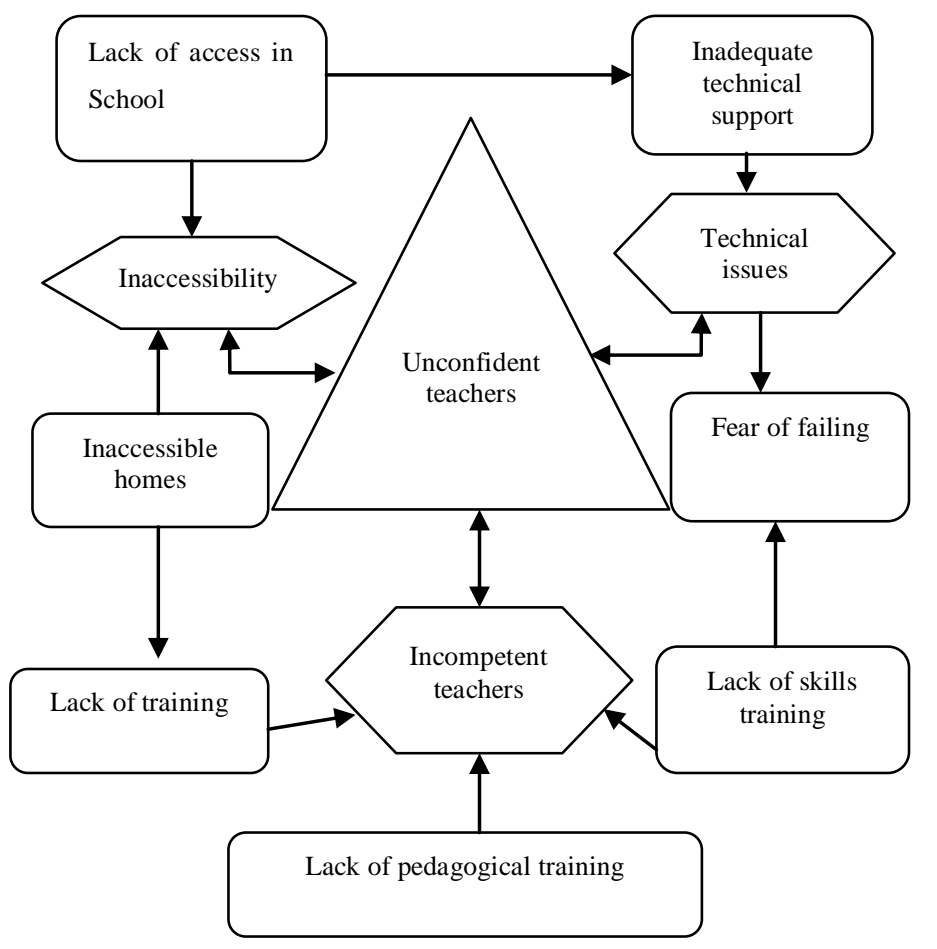

Fig. 3. Integration Of SMART Table And ICT: Intrinsic And Extrinsic Factors

Source: Choy, Berkner, Lee Topper, \& Department of Education (ED) (2009).

To implement ICT and SMART Table effectively into the education system, teachers require proficiency in ICT skills as well as pedagogical acquaintance of efficient ICT teaching practices. Intrinsic variables in computer assimilation comprise positive teaching skill with computers; teacher's acquaintance with computers; beliefs supporting the use of computers as an educational tool; training; motivation; support; and teaching effectiveness. Choy, Berkner, Lee Topper, \& Department of Education (ED) (2010) asserted that ineffective training and inadequate time are barriers that prevent teachers from integrating SMART Table and ICT into the education system. Scott (2009, p. 7) cited "numerous teachers with insufficient competence in ICT feel nervous about using in front of students who are perhaps acquitted to using it. Sub-standard ICT experience comprise factors that may include inadequate skills or insufficient pedagogical training. Moreover, the lack of ample time for teachers to finish their work comprises inadequate time for preparation of the subject, for the discovery and practice of using ICT equipment, and for training; these are also considered significant barriers to the implementation of SMART Table. Ghavifekr, Hussin, \& Ghani (2011) cited that science teachers' motivation is an imperative aspect in introducing ICT, alluding to the inadequacy of time to obtain selfconfidence with ICT, a science curriculum congested with content, and absence of subject-specific direction for using ICT to support learning.

\section{1) Extrinsic Barriers}

Researchers cite that the external barriers that put off the teacher from implementing SMART Table and ICT in the classroom are principally functional: inaccessibility to ICT and internet, inadequate time to build up courses, and unproductive training (Choy, Berkner, Lee Topper, \& Department of Education (ED), 2010). Additional issues cited by authors Kaffash Kargiban, Kargiban \& Ramezani (2010), and Hyland (2010) relate to inadequate organization and technical support, high costs of equipment, and that students lack skills. In addition, the barriers faced in Saudi Arabia, are similar as the ones faced by others in other countries that are the shortage of finance. As you know, technology is relatively expensive, and feasibility means balance between costs of inputs and outputs. The Ministry spares no effort to supply suitable finance, but there are a large number of schools for boys and girls.

Hyland (2010) cites practical issues of resources and access due to the "the lack of high-quality ICT resources in a school will not only prevent teachers from making good use of ICT in their teaching, but will as well have a negative effect on pupils' success" (p. 11). These barriers are summarized in Figure 4.

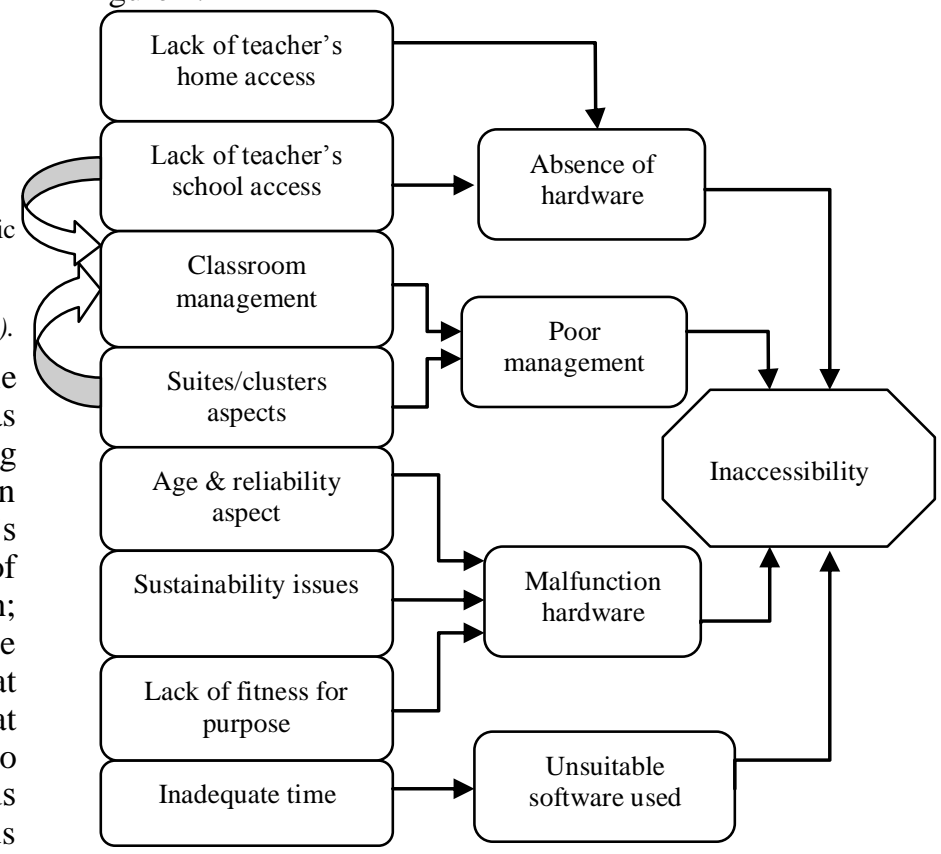

Fig. 4. Issues Regarding Access to SMART Table and ICT Resources

Source: Ghavifekr, Hussin, \& Ghani (2011). 


\section{Potential SMART TABle OUTCOMES}

Application of SMART Table technology within the educational system of Saudi Arabia can result in potentially useful outcomes for the students and teachers. These outcomes are discussed in the following sections.

\section{A. Increased engagement}

A positive outcome is an increase in the level of engagement in the learning process. For example, Tondeur (2010) shared a view and illustrated the interrelationships between ICT, Policy and Management, in which teaching, learning and ICT are in the centre. In order to achieve implementation of the SMART Table strategy in teaching and learning, there should be connectedness and balance between management, and ICT and policy and their different aspects as shown in the following conceptualization.

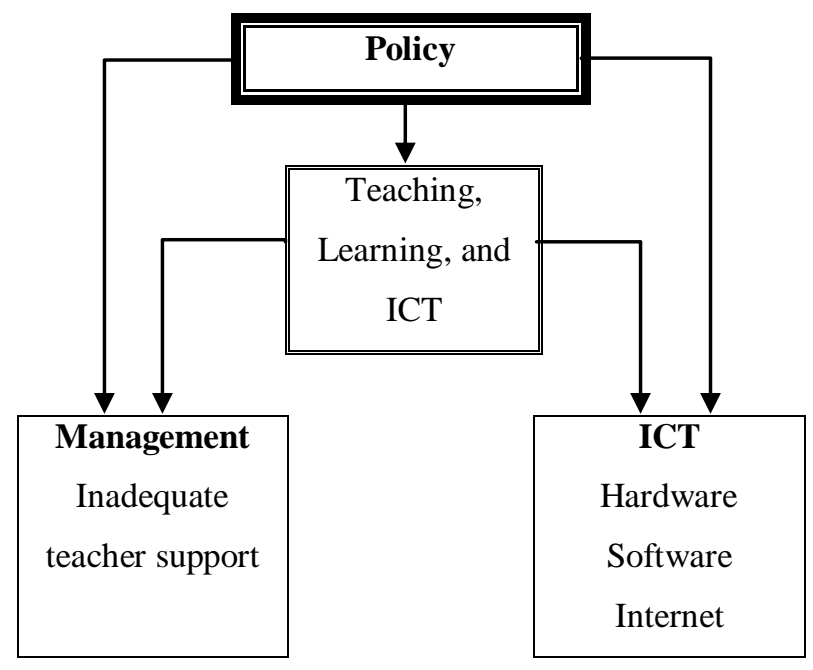

Fig. 5. Interrelationships Between Policy, Management And ICT With Teaching, Learning And ICT

The students, through using SMART Tables, can participate effectively and efficiently in the learning process to enhance their social and academic development. All students can contribute with minimal fear since they develop quality collaboration with the teachers and fellow students. Even the shy students have the chance to participate and enhance their academic and social achievements. Application of SMART Table within the educational system in Saudi Arabia can enable the use of technology in relation to the curriculum.

\section{B. Technological Application}

Since the modern world is increasingly technology oriented, it is vital for students to be technologically confident to meet the requirements of the $21^{\text {st }}$ Century. Technology also enables students to implement the physical world into relevant concepts that are understandable in the elementary aspects. The application of SMART Tables is also beneficial in the expression of learning activities in large formats. This provides the opportunity for students to see and participate during the learning process. This offers the chance for all students including the physically challenged pupils to participate in the interactive learning process. Application of SMART Table can enhance the creation of visual images in the critical thinking of the students. This can assist the understanding process and thus the ability to grasp vital knowledge. The implementation of SMART Tables in the educational system of Saudi Arabia increases the pursuit of knowledge. This is possible since teachers have the opportunity to provide absentee students with relevant information on a previous topic (Khan 2011, p. 889). The notes are also available on the web to offer the chance to students and parents to access the lesson activities. This is elementary towards the development of teachers and students. Teachers reduce the elements of stress that might relate to the preparation of lesson plans and activities. The process enhances the productivity of the teachers in helping students achieve social and academic goals.

\section{DISCUSSION}

This paper has provided an examination of the potential benefits as the barriers for the integration of SMART Table technology in the Saudi education system, and associated implications for teachers' professional development. This discussion relates to the nature of online learning, and expected outcomes and issues pertaining to the introduction of ICT more widely in the classroom. In introducing ICT as a curriculum resource, interlinking enabling and mitigating factors need to be considered. Research elsewhere describes the potential for improved student outcomes (Ghavifekr \& Ghani 2011, p. 86).

\section{A. Implementation of SMART Table}

In order to implement SMART Table and ICT in science education, it is imperative to first identify the specific purpose of that education and match the suitable use of such resources to the accomplishment of those purposes (Kian-sam 2011, p. 1279). Al-Fahad (2010) summarizes the use of ICT in education through three methods: first, learning about the computer with ICT literacy as the objective; second, learning by the computer, in which this type of technology ascertains learning across the curriculum; and the third approach is learning through the computer, incorporating ICT into the curriculum. Using these methods requires extensive professional development for teachers and corresponds to the main purposes of this research study. Developing this theme in a US study, (Kian-Sam \& Songan (2011) accentuates the need for the study of the manner by which ICT integration occurs within schools, factors that increase its acceptance by instructors, and the lasting impacts that such technologies have on instructors and students. Noting its social and economic implications, Bose (2010) nominates four types of approach to using ICT:

a) As delivery: ICT can enhance the manner in which instructional methods are delivered without linking elementary change;

b) As the goal: ICT is the focus of learning new skills; for student understanding: ICT can support students' deep understanding of subjects, as teams of students engage in solving complex, real-world problems; 
c) As knowledge creation: knowledge creation and technological innovativeness can lead to revolution of education system and sustainability of economic and social growth (Bose 2010).

These approaches are grounded in ICT-based methodologies in use today. Online learning, used often by educators and students for out-of-hours communications or distance learning is generally classified into two types: synchronous and asynchronous learning (Bose, 2010). In synchronous online learning, students and their instructors meet over the internet at given times to communicate; whereas with asynchronous online learning students and teachers do not interact live but access the 'virtual' classes from any location at their convenience (Bose). Educators, such as Vanderlinde, Braak \& Tondeur (2010), cite that both types of online learning are powerful tools for teaching and learning. However, there are issues with online instruction; it can have limited capability to engage students unless learners are selfmotivated and well organized in their learning habits (Ghavifekr, Hussin, \& Ghani, 2011).

In Ghavifekr's study, online learners also reported that ICT learning lacked the immediacy of group interchange and lacked empathy between learners and instructors. This factor influences learner satisfaction and learning absorption. Scott (2009) argues that delivering vivid learning experiences to online learners requires a sense of belonging, of immediacy, and a strong learning environment. There is a distinct difference between ICT-based learning opportunities in the developed countries and those of Saudi Arabia (Hyland, 2010). Internet services are limited in Arabic countries due to the government monopolies over the telecommunications sector, resulting in higher prices (Kian-Sam \& Songan, 2011). The authors contend that a very small percent of internet users originate from Arab World, although the Arabic population is very small in comparison to the entire world population. Further, English is generally used for e-learning and most Arab users are not fluent in English, and do not have sufficient familiarity with the language to decipher discipline-based terms and acronyms, or to communicate using English. These factors can distance them from e-learning sources and educational courses. Lastly, social and cultural problems are reflected in varying levels of censorship by Arab governments, as the internet contains opinions that violate Islamic traditions and cultural values (Kian-Sam \& Songan, 2011).

\section{CONCLUSION AND RECOMMENDATIONS}

This paper has argued that SMART Table technology has the potential to be a useful technology for enhancing the educational system in Saudi Arabia. The educational system provides students with equal opportunity to improve their understanding and grasping of relevant concepts. It is crucial for students to enjoy full benefits of the application of technology within the educational system in order to achieve both social and academic goals.

In summary, SMART Table technology enables the creation of learning environments that encourages creativity, teamwork, participation, and interaction between students and teachers. The technology is also essential in relating the physical world to the classroom set-up. This is important for the overall development of the students in areas such as cognition and academic growth. SMART Table set-up also offers the opportunity for students to enhance their scope of pursuit of knowledge thus the perfect scenario to develop effectively and efficiently.

Since technology is essential in so many areas of life in the $21^{\text {st }}$ Century and therefore it is important for new technologies to be integrated into learning environments, the implementation of SMART Tables within the Saudi Arabian educational system is worthy of serious consideration. As discussed in this paper, this can enhance the students' participation in the learning activities, and it is recommended that SMART Tables should be applied in the illustration of complex concepts and collaborative learning within a range of learning areas. This would assist the process of students' acquisition and generation of knowledge. It is also important to promote the adoption of the SMART Table in the educational system to assist teachers in their task of planning for the lessons for all students through catering for the diversity of student learning needs and learning styles (Boss 2010, p. 8).

\section{REFERENCES}

[1] Choy, S, Berkner, L, Lee, J, Topper, A, \& Department of Education (ED), O 2010, 'Academic Competitiveness and SMART Grant Programs: First-Year Lessons Learned', US Department of Education, ERIC,EBSCOhost.Retrievedfrom: http://www2.ed.gov/rschstat/eval/highered/acsmartyear1/acsmart.pdf

[2] Ghavifekr, S, Hussin, S, \& Ghani, M 2011, 'The Process of Malaysian Smart School Policy Cycle: A Qualitative Analysis', Journal of Research \& Reflections In Education (JRRE), 5, 2, pp. 83-104, Education Research Complete, EBSCOhost. Retrieved from: http://www.ue.edu.pk/jrre/articles/52002.pdf

[3] Scott, GA 2009, 'Recent Changes to Eligibility Requirements and Additional Efforts to Promote Awareness Could Increase Academic Competitiveness and SMART Grant Participation', GAO Reports, p. 1, Master FILE Premier, EBSCOhost. Retrieved from: http://www.gao.gov/assets/290/287473.pdf

[4] Hyland, NE 2010, 'Social Justice in Early Childhood Classrooms What the Research Tells Us', YC: Young Children, 65, 1, pp. 82-87, Education Research Complete, EBSCOhost. Retrieved from: http://ucea.org/storage/jrle/pdf/specialissue2010/Christman_JRLE_34.p df

[5] Student Access to Technology-Enabled Education Lags, Survey Finds. (Cover story)' 2010, Electronic Education Report, 17, 2, pp. 1-3, Education Research Complete, EBSCOhost, viewed 8 October 2012.

[6] Options for Whiteboards Are on the Rise' 2010, Electronic Education Report, 17, 2, pp. 3-4, Education Research Complete, EBSCOhost. , viewed 8 October 2012.

[7] Kian-Sam, H, \& Songan, P 2011, 'ICT in the changing landscape of higher education in Southeast Asia', Australasian Journal of Educational Technology, 27, 8, pp. 1276-1290, Education Research Complete, http://www.ascilite.org.au/ajet/ajet27/hong.pdf

[8] Bose, S 2010, 'Enabling Secondary Level Teachers to Integrate Technology through ICT Integrated Instructional System', Online Submission, ERIC, EBSCOhost, viewed 8 October 2012.

[9] Kaffash, H, Kargiban, Z, Kargiban, S, \& Ramezani, M 2010, 'A Close Look in to Role of ICT in Education', Online Submission, ERIC, EBSCOhost. Retrieved from: http://www.eiji.net/dosyalar/iji_2010_2_4.pdf

[10] Kaveie, Z 2011, 'Application of ICT in distance education', Nature \& Science, 9, 8, pp. 50-54, Academic Search Complete, EBSCOhost, viewed 8 October 2012. 
[11] Vanderlinde, R, Braak, J, \& Tondeur, J 2010, 'Using an online tool to support school-based ICT policy planning in primary education', Journal Of Computer Assisted Learning, 26, 5, pp. 434-447, Education Research Complete, EBSCOhost. Retrieved from: http://www.onderwijskunde.ugent.be/downloads/phdRuben_Vanderlinde.pdf

[12] Al-Shehri, AM 2010, 'E-learning in Saudi Arabia: 'To E or not to E, that is the question.", Journal Of Family \& Community Medicine, 17, 3, pp. 147-150, Academic Search Complete, EBSCOhost. Retrieved from: http://www.jfcmonline.com/article.asp?issn=1319-

1683 ; year $=2010 ;$ volume $=17$; issue $=3 ;$ spage $=147$; epage $=150$; aulast $=\mathrm{Al}-$ Shehri

[13] Alenezi, A, Karim, A, \& Veloo, A 2010, 'An Empirical Investigation Into The Role Of Enjoyment, Computer Anxiety, Computer SelfEfficacy And Internet Experience In Influencing The Students' Intention
To Use E-Learning: A Case Study From Saudi Arabian Governmental Universities', Turkish Online Journal Of Educational Technology, 9, 4, pp. 22-34, Education Research Complete, EBSCOhost. Retrieved from: http://www.eric.ed.gov/PDFS/EJ908069.pdf

[14] Al-Fahad, Fahad N. "The Learners' Satisfaction toward Online ELearning Implemented In the College of Applied Studies and Community Service, King Saud University, Saudi Arabia: Can ELearning Replace the Conventional System of Education?" Turkish Online Journal of Distance Education (TOJDE) 11, no. 2 (April 2010): 61-72. Education Research Complete, EBSCOhost. Retrieved from: http://tojde.anadolu.edu.tr/tojde38/pdf/article_2.pdf

[15] Khan, I 2011, 'Professionalization of ELT in Saudi Arabia', Interdisciplinary Journal Of Contemporary Research In Business, 3, 1, pp. 885-895, Business Source Complete, EBSCOhost, viewed 8 October 2012 